\title{
FORMULATION AND EVALUATION OF TRANSDERMAL PATCH OF INDOMETHACIN CONTAINING PATCHOULI OIL AS NATURAL PENETRATION ENHANCER
}

\author{
ASHA DAS ${ }^{1 *}$, ABDUL BAQUEE AHMED \\ ${ }^{1}$ Department of Pharmaceutics, Girijananda Institute of Pharmaceutical Sciences, Azara, Guwahati - 781 017, Assam, India. ${ }^{2}$ Department \\ of Pharmaceutics, Girijananda Chowdhury Institute of Pharmaceutical Science, Azara, Guwahati - 781 017, Assam, India.
}

Email: ashagips@gmail.com

Received: 23 June 2017, Revised and Accepted: 05 August 2017

ABSTRACT

Objective: To develop a transdermal patch of Indomethacin using patchouli oil as a natural enhancer to increase transdermal permeation of the drug from the matrix system across rat epidermis.

Materials and Methods: The chemical characterization of patchouli oil was done by gas chromatography-mass spectrometry. Transdermal patches of indomethacin were formulated after studying the drug-excipient compatibility studies by differential scanning calorimetry and Fourier transform infrared spectroscopy (FTIR). The transdermal patches were evaluated for various physiochemical properties. In-vitro transdermal permeation was carried using modified Keshary-Chein diffusion cell across rat epidermis. FTIR studies of rat epidermis were done to understand the mechanism of the permeation enhancing effect of the oil from the matrix patch.

Result: The results of physiochemical parameters of the transdermal patch were found satisfactory. The transdermal flux obtained of the different concentration of patchouli oil tend to increase with increasing concentration of the oil and the maximum transdermal flux of $61.92 \pm 0.89 \mu \mathrm{g} / \mathrm{cm}^{2} / \mathrm{hr}$ was obtained with formulation F7 (containing 1\% w/v of patchouli oil) which is similar to the flux of the formulation F2 containing standard enhancer dimethyl sulphoxide. The skin irritation test did not show any edema and the FTIR data of rat epidermis indicated that patchouli oil enhances transdermal permeation of indomethacin by partial extraction of lipids in the stratum corneum.

Conclusion: Thus, the results showed a potential enhancing effect of patchouli oil on the transdermal permeation of the model drug indomethacin and may be used as natural permeation enhancer in transdermal drug delivery systems.

Keywords: Patchouli oil, Penetration enhancer, Keshary-Chein diffusion cell, Rat epidermis.

(c) 2017 The Authors. Published by Innovare Academic Sciences Pvt Ltd. This is an open access article under the CC BY license (http://creativecommons. org/licenses/by/4. 0/) DOI: http://dx.doi.org/10.22159/ajpcr.2017.v10i11.20926

\section{INTRODUCTION}

The skin is a large multilayer organ serves as barrier against physical and chemical attack and use as the most desirable site for systemic and topical delivery of drugs because of its easy accessibility [1]. Transdermal drug delivery offers a number of advantages over other conventional methods such as increase patient compliance, sustained release of drugs, and bypassing the gastric first pass metabolism [2].

However, the barrier function of the stratum corneum (outermost layer of the skin) is the main limitation to its use and hence to overcome these barrier properties of the skin penetration enhancers has gain significance in pharmaceutical research [3]. These are the agents helping in increasing the permeation of the skin and are of both natural and synthetic sources which includeazones, pyrrolidones, surfactants, essential oil, etc. [4].

Essential oils are the aromatic compound extracted from natural sources mostly plants, and as skin penetration enhancers they partition into the stratum corneum and cause interaction with components of the tissue to lessen the barrier function of the stratum corneum but do not cause any damage to the skin cell lying underneath [5].

Many types of research have been done to investigated the permeation enhancing effect of essential oils, for example, eucalyptus oil was investigated and it was found to increase permeation of chlorhexidine [6], niaouli oil was investigated and found to be effective as transdermal penetration enhancers for estradiol [7], fennel oil was found to increase the transdermal permeation of trazodone hydrochloride [8].
In this quest of studying the potency of essential oil as permeation enhancers, the present work patchouli oil which is an essential oil was selected to investigate for its penetration enhancing the effect on transdermal patches having indomethacin as a model drug.

Patchouli oil is extracted from Pogostemon cablin of the family Lamiaceae and is been used widely in traditional medicine practices in China and in India [9]. The model drug selected, indomethacin is a non-steroidal anti-inflammatory drug which is used for the treatment of inflammation, arthritis, and pains but on oral administration in chronic treatment causes various gastrointestinal effects as side effects and hence the development of an effective transdermal system will eliminate its side effects [10].

\section{MATERIALS AND METHODS}

\section{Materials}

Chemicals

Patchouli oil was collected from North Eastern Development Finance Corporation Limited, Assam, India. Indomethacin, hydroxypropyl methylcellulose (HPMC K100), polyvinylpyrrolidone (PVP K30) was received from Yarrow Chemical Products (Mumbai, India). Polyethylene glycol (PEG 400) was received from Merck Specialties Pvt. Ltd. (Mumbai, India) and dimethyl sulfoxide (DMSO) was received from Avantor Performance Materials India Limited (Haryana, India). All other reagents and chemicals used throughout the study were of analytical grade.

\section{Animals}

Adult male Wistar albino rats (250-500 g) and adult male New Zealand albino rabbits $(1.5-2 \mathrm{~kg})$ were supplied by Animal House of Girijananda 
Chowdhury Institute of Pharmaceutical Science and was inhabited under standard laboratory condition with proper diet. The animals were received after the proposed study was approved by the Institute Animals Ethics Committee, and Committee for Purpose of Control and Supervision of Experiments on Animals, Government of India bearing the number GIPS/IAEC/M.Ph/2017/03.

\section{Methods}

Physicochemical characterization of the drug and Patchouli oil

Drug (indomethacin)

Odor and color of the drug were observed by smelling and visual inspection, respectively. The melting point of the drug was determined using melting point apparatus (MAC, Digital melting point apparatus, Macro Scientific Works).

Patchouli oil

The color, odor, and solubility of the essential oil in organic solvents were checked manually and the viscosity of the oil was measured using a Brookfield DV-E viscometer.

Chemical characterization by gas chromatography-mass spectrometry (GC-MS)

The GC-MS analysis of the oil was performed on a Parkin Elmer Clarus $680 / 600$ chromatogram with build in autosampler using a fused DB-5 capillary column (length $30 \mathrm{~m} \times 0.25 \mathrm{~mm}$ internal diameter (ID), film thickness $0.25 \mu \mathrm{m}$ ), equipped with an Elite-5 MS capillary column and FID detector. The oven temperature was programmed from $50^{\circ}$ to $260^{\circ} \mathrm{C}$ at a rate of $5^{\circ} \mathrm{C} / \mathrm{min}$. The injector temperature was set at $250^{\circ} \mathrm{C}$ and the injection volume was $1.0 \mu \mathrm{L}$. The run time was 46 minutes the gas used was helium with a flow rate of $1.1 \mathrm{~mL} / \mathrm{min}$ [11]

\section{Drug-excipient compatibility study}

The compatibility study of the drug with excipients to be used in the formulations was done by Fourier transform infrared spectroscopy (FTIR) and differential scanning calorimetry (DSC) studies [12-14].

\section{FTIR study}

The compatibility of the drug with excipients was studied using a Bruker FTIR spectrophotometer (model 220, Germany) in the range 4000$400 \mathrm{~cm}^{-1}$. The FTIR spectra of drug, excipients, and physical mixture of drug-excipient are compared for presence or absence of incompatibility.

\section{DSC study}

For thermal analysis of Indomethacin and Indomethacin-excipient mixtures, a differential scanning calorimeter (Jade DSC, Perkin Elmer 2000, USA) was used. Individual samples of indomethacin, excipients, and physical mixtures of indomethacin and selected excipients were mixed in the ratio $1: 1$ and scanned in the temperature range of $20-300^{\circ} \mathrm{C}$ under an atmosphere of dry nitrogen at a heating rate of $10^{\circ} \mathrm{C} /$ minute. The thermograms hence obtained were checked for any interaction.

\section{Preparation of transdermal patch}

Transdermal patches (matrix type) were prepared using solvent evaporation technique. In this method bangles are used, the bottom of which are covered with aluminum foil. The transdermal patches were prepared in accordance with the formula shown in Table 1. HPMC (K100) and PVP (K30) in requisite amount were measured and dissolved in the solvent containing chloroform and ethanol in the ratio 1:1. Indomethacin was added to the homogeneous dispersion followed by addition of PEG which was used as a plasticizer. The uniform dispersion was then cast to the aluminum backing membrane; the evaporation rate was controlled using inverting funnel over the patches. After $24 \mathrm{hrs}$, the dried films were taken out, wrapped in aluminum foil and kept in a desiccator for further use [15].

\section{Evaluation of transdermal patches \\ Folding endurance}

The evaluation of folding endurance was done by cutting a strip of a specific area which was repeatedly folded at the same place without breaking and which gives the value of folding endurance [16].

\section{Film thickness}

The film thickness was evaluated by measuring the film at different places using a screw gauge and taking the average of five readings [17].

\section{Drug content}

For estimating drug content, a required area of the patch is cut and is put into $100 \mathrm{ml}$ phosphate buffer (pH 7.4) shaken continuously for $24 \mathrm{hrs}$. The solution is then subjected to ultrasonication for 15 minutes and after which it is filtrated and the drug content is analyzed by ultraviolet spectrophotometer at lambda max $\left(\lambda_{\max }\right)$ of $256 \mathrm{~nm}$ [18].

\section{Uniformity of weight}

Uniformity of weight is determined by weighing individually 10 randomly selected patches and then the average weight is calculated [19].

\section{Skin irritation study}

For performing skin irritation study healthy rabbits (average weight $1.2-1.5 \mathrm{~kg}$ ) were taken and the samples were applied on the dorsal surface of the rabbit skin, hair of which was removed by shaving and cleaned with rectified spirit. Adhesive tape USP was used as control patch. The formulations (transdermal patch) were removed after $24 \mathrm{hrs}$ and the skin was examined for erythema/edema [20].

\section{Skin preparation and in-vitro permeation study}

Preparation of rat skin

The rat skin was prepared by first anesthetizing the male Wistar albino rats with chloroform after which they were sacrificed. The abdominal hair was shaven with the help of electrical clipper, then the epidermal layer was surgically removed and then to remove the adhering fat it was wiped with isopropyl alcohol, it was then soaked in phosphate buffer $\mathrm{pH}$ 7.4, wrapped in aluminum foil, and kept in the deep freezer for further studies [21].

Permeation study

The in-vitro permeation study was done using a modified Keshary-Chein diffusion cell using rat epidermis. The rat epidermis was mounted

Table 1: Formulation composition of patches containing indomethacin

\begin{tabular}{|c|c|c|c|c|c|c|}
\hline Formulation code & HPMC K100 (mg) & PVP K30 (mg) & PEG 400 (ml) & Indomethacin (mg) & DMSO (\% w/v) & Patchouli oil (\% w/v) \\
\hline $\mathrm{F} 1$ & 130 & 160 & 0.3 & 30 & - & - \\
\hline F2 & 130 & 160 & 0.3 & 30 & 0.05 & - \\
\hline F3 & 130 & 160 & 0.3 & 30 & - & 0.05 \\
\hline $\mathrm{F} 4$ & 130 & 160 & 0.3 & 30 & - & 0.25 \\
\hline F5 & 130 & 160 & 0.3 & 30 & - & 0.5 \\
\hline F6 & 130 & 160 & 0.3 & 30 & - & 0.75 \\
\hline F7 & 130 & 160 & 0.3 & 30 & - & 1.0 \\
\hline
\end{tabular}

HPMC K100: Hydroxypropyl methyl cellulose, PVP: Polyvinyl pyrolidone, PEG 400: Polyethylene glycol, DMSO: Dimethyl sulphoxide 
between the donor and the receptor compartment of the diffusion cell and the patch was cut into requisite shape and placed over epidermis in the donor compartment. The permeation study was carried for $8 \mathrm{hrs}$ with the receptor compartment containing $34 \mathrm{ml}$ of phosphate buffer $\mathrm{pH} 7.4$ maintained at $37 \pm 0.5^{\circ} \mathrm{C} .2 \mathrm{ml}$ of sample at different intervals was withdraw and analyzed spectrophotometrically at $\lambda_{\text {max }}$ of $256 \mathrm{~nm}$ against blank and receptor phase was replaced with equal volume of phosphate buffer at each intervals. Cumulative release curve per $\mathrm{cm}^{2}$ of the patch was plotted against time and the permeation parameters of indomethacin across rat epidermis treated with patch containing patchouli oil were compared with the placebo patch and appropriate control (DMSO) [22,23].

Permeation enhancement mechanistic study

The permeation enhancement mechanistic study was done by FTIR study of rat epidermis treated with the transdermal patch without the essential oil (patchouli oil) as a permeation enhancer and of the epidermis treated with the patch containing the essential oil (patchouli oil).

\section{Data analysis}

For estimating the in-vitro release parameters, the flux of indomethacin across rat epidermis was calculated from the slope of cumulative release curve per $\mathrm{cm}^{2}$ of the patch cross the skin versus time using linear regression analysis. The lag time $\left(\mathrm{T}_{\mathrm{lag}}\right)$ was calculated from the $\mathrm{X}$-intercept from the linear portion of the plot, the cumulative amount of drug permeated $Q_{24}(\mu \mathrm{g} / \mathrm{hr})$ was the amount of drug penetrating through the skin after 24 hrs. The enhancer ratio was also estimated using the equation: $\mathrm{E}_{\mathrm{SS}}=\mathrm{J}_{\mathrm{SS}}$ (enhancer treated) $/ \mathrm{J}_{\mathrm{ss}}$ (control). All the data, hence, found was expressed as a mean \pm standard deviation (SD) [24-26].

The therapeutic transdermal daily dose for indomethacin was calculated using the equation: $\mathrm{T}_{d}=\mathrm{D}_{0} \times \mathrm{F} / 100$, where $\mathrm{D}_{0}$ is the oral dose $\mathrm{F}$ is the bioavailability after oral administration in percentage [27].

\section{RESULTS AND DISCUSSION}

\section{Physiochemical evaluation of drug and oil}

\section{Physiochemical properties of drug}

After proper observations, indomethacin was found to be colorless, odorless and it was soluble in ethanol, methanol, and acetone and the melting point of the drug sample was found to be $162 \pm 0.5^{\circ} \mathrm{C}$ (mean \pm $\mathrm{SD}, \mathrm{n}=3)$.

\section{Physiochemical properties of oil}

The results of physicochemical evaluation of the patchouli oil are presented in Table 2.

\section{GC-MS analysis of patchouli oil}

After performing the GC-MS study of the patchouli oil resulted in the identification of 16 components of the major peaks in the gas chromatogram. The results hence found are given in Fig. 1 and Table 3.

\section{Drug excipient compatibility studies}

FTIR spectroscopy

All the characteristic peaks of the pure drug indomethacin were retained in drug and polymer physical mixtures, which indicate that the drug and polymer are compatible. The results of the FTIR studies were shown in Table 4 and in the Fig. 2.

\section{DSC studies}

From the DSC studies, the results were shown in Fig. 3. The melting point of Indomethacin was found to be at $162.89^{\circ} \mathrm{C}$, a mixture of HPMC $\mathrm{K} 100+$ indomethacin and PVP $\mathrm{K} 30+$ indomethacin at $161.68^{\circ} \mathrm{C}$ and $153.63^{\circ} \mathrm{C}$, respectively, which were in range and thus it was concluded that no type of drug excipient compatibility was found.
Table 2: Physiochemical properties of oil

\begin{tabular}{lll}
\hline S.No. & Parameters & Results \\
\hline 1 & Color & Slightly brown \\
2 & Odor & Characteristic unpleasant \\
3 & Taste & Characteristic pungent \\
4 & Solubility & Chloroform, acetone \\
5 & Density & $0.963 \pm 0.07 \mathrm{~g} / \mathrm{mol}$ \\
6 & Viscosity $(\mathrm{cP})$ & $509 \mathrm{cP}(50 \mathrm{rpm} / \mathrm{min})^{*}$ \\
& & $307 \mathrm{cP}(100 \mathrm{rpm} / \mathrm{min})^{*}$ \\
\hline
\end{tabular}

${ }^{*}$ All the values are given in mean \pm SD $(n=3)$. $\mathrm{P}$ : Centipoise, SD: Standard deviation

Table 3: Identified components of patchouli oil

\begin{tabular}{llll}
\hline S.No. & Compound & $\begin{array}{l}\text { Retention } \\
\text { time } \\
\text { (minutes) }\end{array}$ & \% Area \\
\hline 1 & 1,5-cyclodecadiene & 26.031 & 1.618 \\
2 & 4,7-methanoazulene & 26.091 & 1.524 \\
3 & Caryophyllene & 26.996 & 3.831 \\
4 & Azulene & 27.371 & 14.274 \\
5 & Seychellene & 28.926 & 1.359 \\
6 & 1H-cycloprop[e]azulene & 28.817 & 2.849 \\
7 & 1,4-methanocycloocta(D) & 29.157 & 0.187 \\
& pyridazine & 30.682 & 0.698 \\
8 & 7-methannoaazulene & 30.927 & 0.711 \\
9 & Cyclohexanone & 31.047 & 0.836 \\
10 & Icosapent & 32.078 & 1.005 \\
11 & gamma-Elemene & 32.318 & 0.204 \\
12 & Methyl 8,11,14-heptadecatrienoate & 32.938 & 2.900 \\
13 & Naphthalene & 33.398 & 36.708 \\
14 & Patchouli alcohol & 34.549 & 0.165 \\
15 & 1-propyl 6,9,12-hexadecatrienoate & 35.594 & 0.194 \\
\hline 16 & 2-allyl-4 methylphenol & & \\
\hline
\end{tabular}

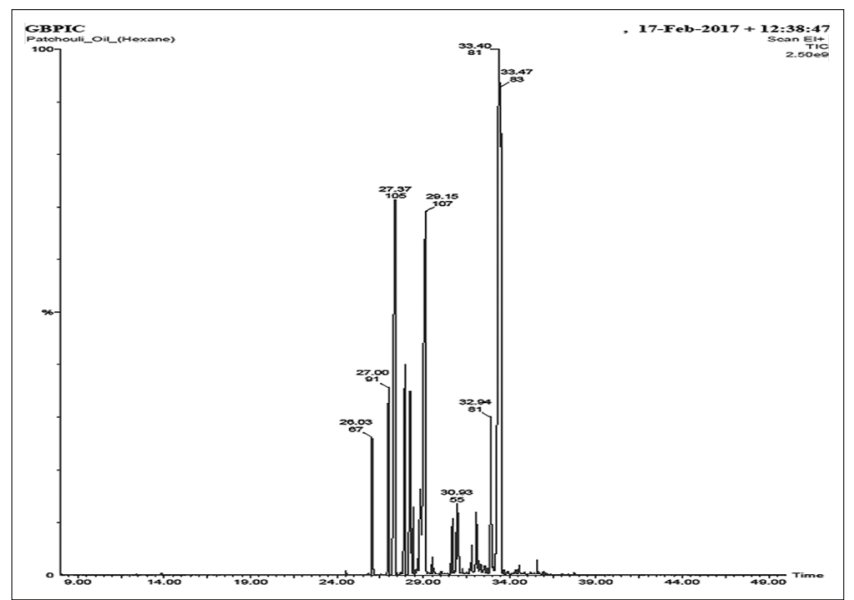

Fig. 1: Gas chromatography-mass spectrometry chromatogram of patchouli oil

\section{Evaluation of transdermal patch}

The results of evaluation of various physiochemical parameters of indomethacin transdermal patches were presented in Table 5. The values of weights and thickness were found to be uniform having an almost low value of SD. The drug content was also studied for all the formulations indicating that the method used for the preparation of transdermal patch was suited for giving uniform drug content.

\section{Skin irritation study}

On performing skin irritation study test for formulation F7on healthy, a male rabbits for $24 \mathrm{hrs}$ and comparing it to the control (adhesive tape USP); 
Table 4: FTIR interpretation of drug and excipients

\begin{tabular}{|c|c|c|c|}
\hline \multirow[t]{2}{*}{ Functional group } & \multicolumn{3}{|c|}{ Wave number $\left(\mathrm{cm}^{-1}\right)$} \\
\hline & Indomethacin & Indomethacin + HPMC K100 & Indomethacin + PVP K30 \\
\hline $\mathrm{O}-\mathrm{H}$ bending & 1219.81 & 1219.99 & 1289.41 \\
\hline C-Cl stretching & 749.22 & 749.25 & 750.53 \\
\hline C-O stretching & 1064.20 & 1083.84 & 1065.91 \\
\hline C-C stretching & 831.51 & 831.50 & 831.50 \\
\hline
\end{tabular}

HPMC K100: Hydroxypropylmethylcellulose, PVP K30: Polyvinylpyrrolidone, FTIR: Fourier transform infrared

Table 5: Drug content and physical parameters of different formulation of patch

\begin{tabular}{llll}
\hline Formulation code & Film thickness $(\mathbf{m m})^{*}$ & Folding endurance** $^{*}$ & Uniformity of weight (mg)* $^{*}$ Drug content* \\
\hline F1 & $0.130 \pm 0.0026$ & 7 & $530.8 \pm 1.65$ \\
F2 & $0.132 \pm 0.0023$ & 6 & $537.1 \pm 1.71$ \\
F3 & $0.129 \pm 0.0028$ & 4 & $525.6 \pm 1.86$ \\
F4 & $0.121 \pm 0.0030$ & 5 & $534.5 \pm 1.92$ \\
F5 & $0.128 \pm 0.0029$ & 7 & $536.2 \pm 2.14$ \\
F6 & $0.132 \pm 0.0014$ & 6 & $529.8 \pm 1.69$ \\
F7 & $0.120 \pm 0.0032$ & 4 & $539.3 \pm 1.76$ \\
\hline
\end{tabular}

*All the values are given in mean \pm SD $(n=3)$, **average of 3 observations. SD: Standard deviation

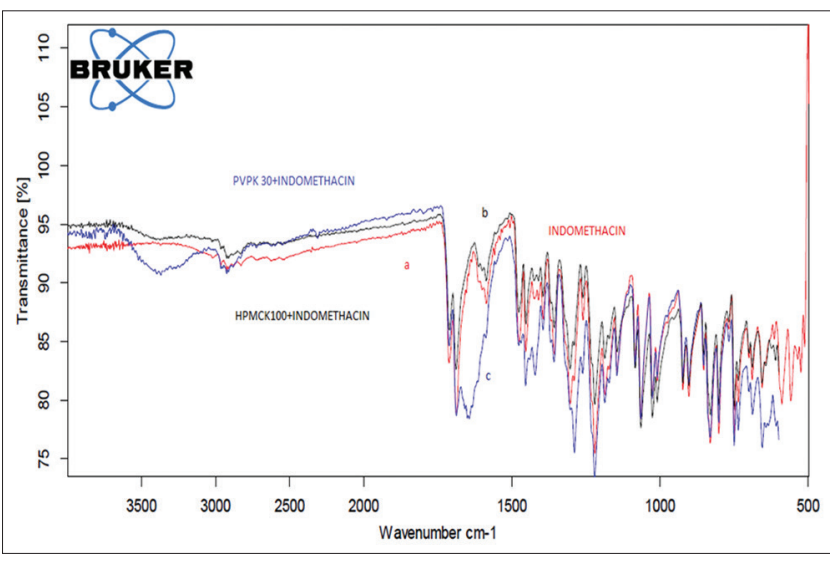

Fig. 2: Fourier transform infrared spectroscopy (FTIR) spectra of drug, excipients, and physical mixture of drug and excipients. (a) FTIR spectra of indomethacin, (b) FTIR spectra of hydroxypropyl methylcellulose K100M + indomethacin, (c) FTIR spectra of polyvinylpyrrolidone $\mathrm{K30}+$ indomethacin

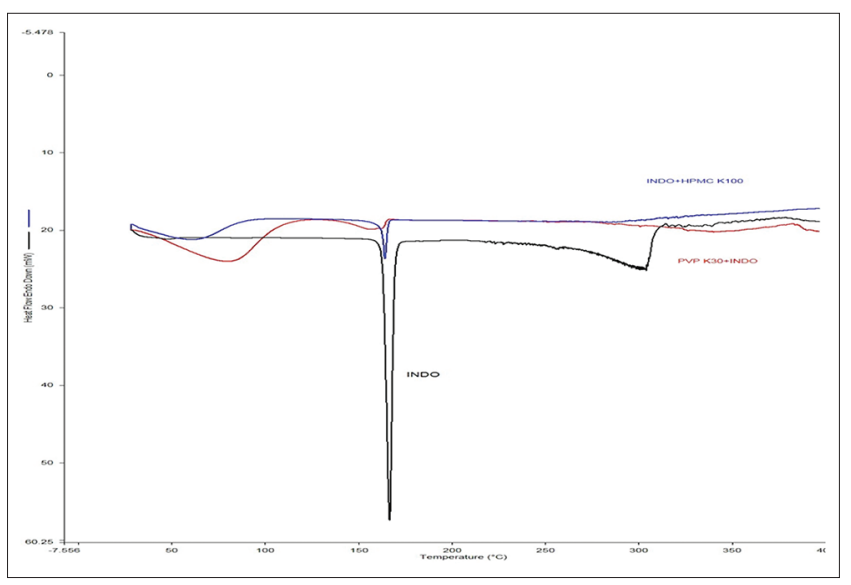

Fig. 3: Differential scanning calorimetry (DSC) thermogram of drug, excipients, and physical mixture of drug and excipients. (a) DSC thermogram of indomethacin, (b) DSC thermogram of hydroxypropyl methylcellulose K100M + indomethacin, (c) DSC thermogram of polyvinylpyrrolidone $\mathrm{K30}+$ indomethacin no edema or erythema was observed on the site of application of the patch indicating that they are non-irritable to the skin hence can be considered safe for transdermal patches. The observed results are depicted in Fig. 4.

\section{Permeation study}

All the seven formulations were subjected to in-vitro permeation studies across rat epidermis for establishing the different permeation parameters. The results of permeation studies were shown in Table 6 and Fig. 5. From the data of the study, it was revealed that the transdermal flux of the formulation F1 which contains only the drug is $8.82 \pm 0.26 \mu \mathrm{g} / \mathrm{cm}^{2} / \mathrm{hr}$, which is very less in comparison to the flux value of $62.32 \pm 1.09 \mu \mathrm{g} / \mathrm{cm}^{2} / \mathrm{hr}$ of the F2 formulation containing DMSO as the standard permeation enhancer.

The formulations containing the different concentrations of patchouli oil, namely, F3 (containing $0.05 \% \mathrm{w} / \mathrm{v}$ of patchouli oil), F4 (containing $0.25 \% \mathrm{w} / \mathrm{v}$ of patchouli oil), F5 (containing $0.50 \% \mathrm{w} / \mathrm{v}$ of patchouli oil), F6 (containing $0.75 \% \mathrm{w} / \mathrm{v}$ of patchouli oil), and F7 (containing $1 \% \mathrm{w} / \mathrm{v}$ of patchouli oil) shows increase in transdermal flux with the increasing concentration of patchouli oil showing the flux to be $40.99 \pm$ $2.77 \mu \mathrm{g} / \mathrm{cm}^{2} / \mathrm{hr}, 46.64 \pm 1.54 \mu \mathrm{g} / \mathrm{cm}^{2} / \mathrm{hr}, 54.5 \pm 2.76 \mu \mathrm{g} / \mathrm{cm}^{2} / \mathrm{hr}, 56.88$ $\pm 1.43 \mu \mathrm{g} / \mathrm{cm}^{2} / \mathrm{hr}$ and $61.92 \pm 0.89 \mu \mathrm{g} / \mathrm{cm}^{2} / \mathrm{hr}$, respectively. The cumulative amount $\left(\mathrm{Q}_{24}\right)$ of indomethacin permeated over $24 \mathrm{hrs}$ was found to increase, ranging from $1830 \pm 26.66$ to $2660 \pm 21.60 \mu \mathrm{g} / \mathrm{cm}^{2}$ from the transdermal patches containing $0.05-1 \% \mathrm{w} / \mathrm{v}$ of patchouli oil. This result evidenced that the addition of patchouli oil in the formulation enhanced the transdermal flux of indomethacin which is as comparable as with DMSO used as a standard permeation enhancer.

\section{Permeation enhancement mechanistic study}

FTIR study

To further elucidate the effect of patchouli oil-induced alteration on the intercellular lipids in the stratum corneum keratin and protein FTIR studies were conducted of rat epidermis one as control (epidermis treated with a patch containing no penetration enhancer) and one as at test (epidermis treated with a patch containing patchouli oil as penetration enhancer). The spectra showed a number of peaks due to molecular vibrations of the proteins of the stratum corneum. After scanning the rat epidermis (both control and test) by FTIR, the spectra showed absorption bands at $2921 \mathrm{~cm}^{-1}$ (C-H stretching) and $2852 \mathrm{~cm}^{-1}$ (C-H stretching) which are in the range from 2700 to $3000 \mathrm{~cm}^{-1}$, which occurs mainly due to the $\mathrm{C}-\mathrm{H}$ stretching of the alkyl groups present in the lipids and the proteins [28]. 
Table 6: Permeation parameters of the different formulations of transdermal patches of indomethacin studied across rat skin

\begin{tabular}{|c|c|c|c|c|}
\hline Formulation code & $Q_{24}\left(\mu \mathrm{g} / \mathrm{cm}^{2}\right)^{\mathrm{a}}($ mean $\pm S D ; \mathrm{n}=3)$ & $\mathrm{J}\left(\mu \mathrm{g} / \mathrm{cm}^{2} / \mathrm{hr}\right)^{\mathrm{b}}($ mean $\pm S D ; \mathrm{n}=3)$ & $\mathrm{T}_{\text {lag }}(\mathrm{hr})^{\mathrm{c}}($ mean $\pm S D ; \mathrm{n}=3)$ & $\mathrm{ER}^{\mathrm{d}}($ mean $\pm S D ; n=3)$ \\
\hline F1 & $395.5 \pm 6.53$ & $8.82 \pm 0.26$ & $3.20 \pm 0.76$ & - \\
\hline F2 & $2752 \pm 54.00$ & $62.32 \pm 1.09$ & $2.40 \pm 0.65$ & $7.06 \pm 0.10$ \\
\hline F3 & $1830 \pm 26.66$ & $40.99 \pm 2.77$ & $1.50 \pm 0.38$ & $4.64 \pm 0.31$ \\
\hline F4 & $2061 \pm 42.00$ & $46.64 \pm 1.54$ & $2.12 \pm 0.48$ & $5.28 \pm 0.17$ \\
\hline F5 & $2201 \pm 79.33$ & $54.5 \pm 2.76$ & $2.10 \pm 0.53$ & $6.12 \pm 0.35$ \\
\hline F6 & $2535 \pm 20.00$ & $56.88 \pm 1.43$ & $1.90 \pm 0.30$ & $6.44 \pm 0.09$ \\
\hline F7 & $2660 \pm 21.60$ & $61.92 \pm 0.89$ & $1.20 \pm 0.46$ & $7.02 \pm 0.10$ \\
\hline
\end{tabular}

${ }^{\mathrm{a}} \mathrm{Q}_{24}$ cumulative release of drug in $\mu \mathrm{g} / \mathrm{cm}^{2}$ at the end of $24 \mathrm{hrs}$; ${ }^{\mathrm{b} J}$ flux of the different formulations; ${ }^{\mathrm{T}} \mathrm{T}_{\text {lag }}$ is the lag time of the different formulations; ${ }^{\mathrm{d}} \mathrm{ER}$ is the enhancement ratio of indomethacin. SD: Standard deviation

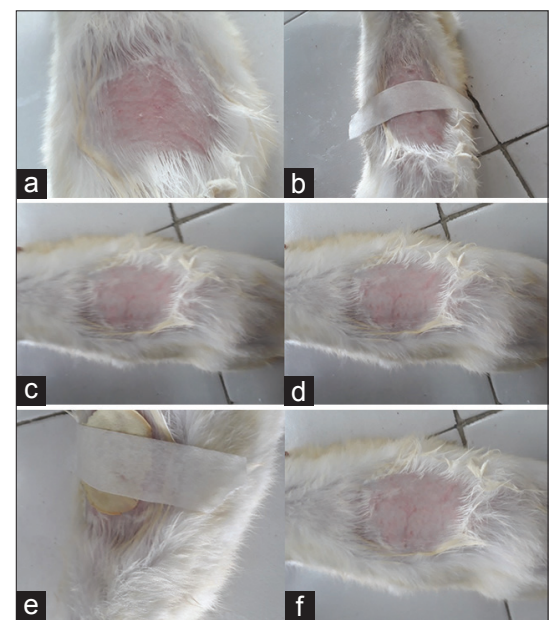

Fig. 4: Photographs of skin irritation study, (a) Before application of transdermal patch, (b) application of adhesive tape USP,

(c) After application of adhesive tape USP, (d) before application of transdermal patch, (e) application of transdermal patch, (f) after application of transdermal patch

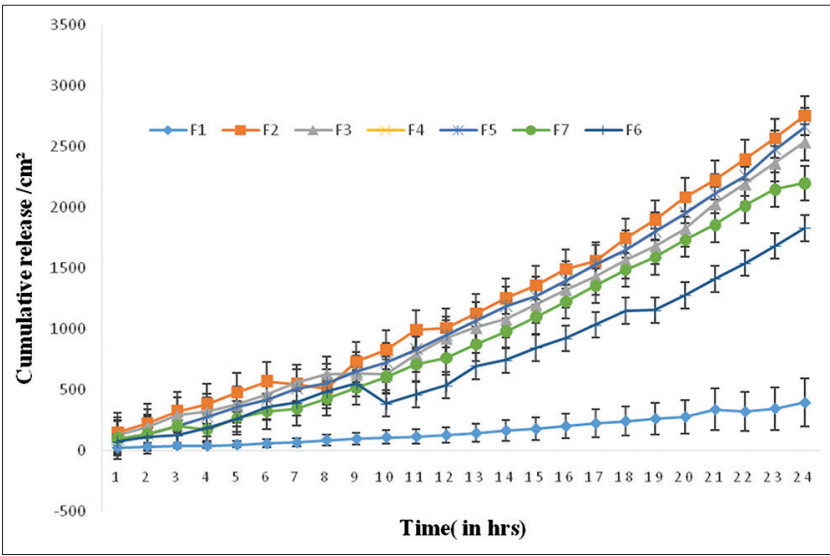

Fig. 5: In-vitro skin permeation profiles of various transdermal formulations. All the values are given in mean \pm standard deviation, $n=3$

It also showed 2 amide vibrations within the range of $1500 \sim 1700 \mathrm{~cm}^{-1}$, namely, amide $1\left(\sim 1644 \mathrm{~cm}^{-1}\right)$ and amide $2\left(\sim 1539 \mathrm{~cm}^{-1}\right)$, which were one of the important parameters to investigate the alteration in the structure of the lipids and keratin present in stratum corneum induced by penetration enhancers [29]. The frequencies of these amide bonds shifts to lower or higher frequencies due to change in protein conformation [29] and from the spectra (Fig. 6) it was seen that the frequency of the amide band of the test shifted toward the higher frequency in comparison to the control which helps us to conclude that the essential oil under investigation (patchouli oil) enhances the

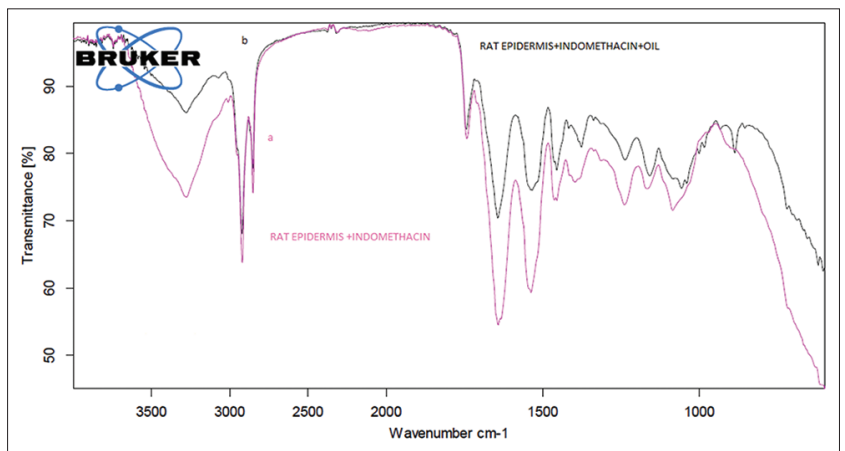

Fig. 6: (a) Fourier transform infrared spectroscopy (FTIR) spectra of untreated ratepidermis, (b) FTIR spectra of rat epidermis treated with patchouli oil as penetration enhancer

permeation by possible disruption of stratum corneum lipids and also by changing protein conformations.

\section{CONCLUSION}

In the present study, various formulations of transdermal indomethacin patches were prepared and the effect of patchouli oil was investigated for its permeation property. On account of the results, it was found that all the prepared formulations showed good uniformity with regard to drug content and physical parameters. The skin irritation study performed indicated that the patches showed no skin irritation exhibited by patchouli oil. The in-vitro skin permeation studies showed that patchouli oil can remarkably enhance the permeation of indomethacin across rat epidermis with increasing concentration of patchouli oil. The FT-IR studies showed that patchouli oil brings changes in the stratum corneum lipids and protein conformation which possibly results in the alteration of skin permeability. Hence, it can be concluded that patchouli oil can effectively enhance the transdermal permeation of model drug indomethacin and may be used as a natural permeation enhancer for transdermal drug delivery system.

\section{ACKNOWLEDGMENT}

Foremostly, I will like to thanks my guide associate professor Dr. Abdul Baquee Ahmed for his guidance and support throughout the project. I will also like to pay my sincere gratitude to my principal Dr. Suvakanta Dash for giving me the opportunity to do the research work. The authors are also thankful to Yarrow Chemical Products (Mumbai, India) for providing with Indomethacin and also Girijananda Chowdhury Institute of Pharmaceutical Sciences for providing all the facilities for the study.

\section{REFERENCES}

1. Chen J, Jiang QD, Wu YM, Liu P, Yao JH, Lu Q, et al. Potential of essential oils as penetration enhancers for transdermal administration of ibuprofen to treat dysmenorrhoea. Molecules 2015;20(10):18219-36.

2. Karande P, Mitragotri S. Enhancement of transdermal drug delivery via synergistic action of chemicals. Biochim Biophys Acta 2009; 1788(11):2362-73 
3. Chantasart D, Li SK. Structure enhancement relationship of chemical penetration enhancers in drug transport across the stratum corneum. Pharmaceutics 2012;4(1):71-92.

4. Goswami D, Uppal N, Goyal S, Mehta N, Gupta AK. Permeation enhances for TDDS from natural and synthetic sources: A review. J Biomed Pharm Res 2013;2(1):19-29.

5. Aggarwal S, Agarwal S, Jalhan S. Essential oil as novel human skin penetration enhances for transdermal drug delivery: A review. Int J Pharm Bio Sci 2013;4(1):857-68

6. Karpanen TJ, Conway BR, Worthington T, Hilton AC, Elliott TS, Lambert PA. Enhanced chlorhexidine skin penetration with eucalyptus oil. BMC Infect Dis 2010;10:278.

7. Monti D, Chetoni P, Burgalassi S, Najarro M, Saettone MF, Boldrini E. Effect of different terpene-containing essential oils on permeation of estradiol through hairless mouse skin. Int J Pharm 2002;237(1-2):209-14.

8. Das MK, Bhattacharya A, Ghoshal SK. Effect of different terpene-containing essential oil on percutaneous absorption of trazodone hydrochloride through mouse epidermis. J Drug Deliv 2006;13(6):425-31.

9. Swamy MK, Sinniah UR. A comprehensive review on phytochemical constituents and pharmacological activities of pogostemoncablin Benth.: An aromatic medicinal plant of industrial importance. Molecules 2015;20(5):8521-47.

10. Shakeel F, Ramadan W, Gargum HM, Singh R. Preparation and in vivo evaluation of indomethacin loaded true nanoemulsions. Sci Pharm 2010;78(1):47-56.

11. Majunder M, Sharma HK, Tamam K, Lyngdoh W. Evolution of physicochemical properties and antibacterial activity of essential oil obtained from the fruits of lynthoxyylleem acanthopodium DC. Collected from Meghalaya. Int J Pharm Pharm Sci 2014;6(3):543-6.

12. Subhash PG, Dinesh BM, Ravikumar M. Feasibility of lercanidipine $\mathrm{HCl}$ for TDDS: Presence of various penetration enhancers. Int J Pharm Pharm Sci 2011;3(4):103-7.

13. Ahmed AB, Nath LK. Drug-exipients compatibility studies of nicorandil in controlled release floating tablets. Int J Pharm Pharm Sci 2014;6(4):468-75

14. Prabhakar D, Sreekanth J, Jayaveera KN. Development and evaluation of transdermal patches of azelnidipine. Int $\mathrm{J}$ Pharm Pharm Sci 2013;5(3):805-10

15. Sheth NS, Misty RB. Formulation and evaluation of transdermal patches and to study permeation enhancement effect of eugenol. J Appl Pharm Sci 2011;1(3):96-101.

16. Dhiman S, Singh TG, Rehni AK. Transdermal patches: A recent approach to new drug delivery system. Int $\mathrm{J}$ Pharm Pharm Sci 2011;3(5):26-34

17. Amnuaikit C, Ikeuchi I, Ogawara K, Higaki K, Kimura T. Skin permeation of propranolol from polymeric film containing terpene enhancers for transdermal use. Int J Pharm 2005;289(1-2):167-78.

18. Sachan R, Bajpai M. Transdermal drug delivery system: A review. Int J Res Dev Pharm Life Sci 2013;3(1):748-65.

19. Alam MI, Alam N, Singh V, Alam MS, Ali MS, Anwer T, et al. Type preparation and evaluation of transdermal patch: A review. World J Pharm Sci 2013;2(4):2199-233.

20. Sharan G, Dey BK, Nagarajan K, Das S, Kumar SV, Denish V. Effect of various permeation enhances on propanolol hydrochloride formulated patches. Int J Pharm Pharm Sci 2010;2(2):21-31.

21. Kumar A, Geeta A, Singh K. Comparison of vegetables and volatile oils as skin permeation enhancersfor transdermal drug delivery of losartan potassium. Pharm Lett 2014;6(1):199-213.

22. Ravichanderan V, Manivannam S. Wound healing potential of transdermal patches containing bioactive fraction from the bark of Ficus racemosa. Int J Pharm Pharm Sci 2015;7(6):326-32.

23. Jain DK, Darwhekar GN, Chaurasia S. Formulation development and evaluation of transdermal patches of losartan. Int J PharmTech Res 2012;4(2):757-64

24. Patel RP, Patel G, Baria A. Formulation and evaluation of transdermal patches of aceclofenac. Int J Drug Deliv 2009;1:41-51.

25. Julraht K, Keith AP, James AW. Development of a transdermal delivery device for melatonin in-vitro study. Drug Dev Ind Pharm 1995;21:1377-87.

26. Krishnaiah YS, Kumar MS, Raju V, Lakshmi M, Rana B. Penetrationenhancing effect of ethanolic solution of menthol on transdermal permeation of ondasetron hydrochloride across rat epidermis. Drug Deliv 2008;15(4):227-34.

27. Vaddi HK, Ho PC, Chan YW. Terpenes of propylene glycol as skinpenetration enhances: Permeation and partition of haloperidol, Fourier leansforminfeared spectroscopy, and differential scanning caloriuetry. J Pharm Sci 2009;91(7):1639-51

28. Vashhisth I, Ahad A, Aquil M, Agarwal SP. Investigating the potential of essential oil as penetration enhances for transdermal losartan delivery: Effectiveness and mechanism of action. Asian J Pharm Sci 2014;9(5):260-7.

29. Xie F, Chai JK, Hu Q, Yu YH, Ma L, Liu LY, et al. Transdermal permeation of drugs with differeninglipophilicity: Effect of penetration enhancer camphor. Int J Pharm 2016;507(1-2):90-101. 